\title{
On Japanese Culture Education in Japanese Teaching Qiaoying Liu
}

School of Foreign Languages and Cultures, Ningxia University, Yinchuan Ningxia, 750021, China

Keywords: Japanese culture, Japanese, Teaching, Countermeasures.

\begin{abstract}
The ultimate goal of Japanese teaching is to use language to carry out in-depth communication. Accurate and appropriate Japanese language expressive ability is only one of the steps of learning. However, if you want to carry out comprehensive and in-depth use of Japanese to communicate, you need a comprehensive understanding of Japanese Reflected in the Japanese culture, so as to be able to use Japanese faster to improve the effectiveness of learning. On the basis of summarizing Japanese and Japanese culture, this paper expounds the necessity of incorporating Japanese culture education into Japanese teaching, and puts forward some countermeasures to use Japanese culture education to carry out Japanese teaching.
\end{abstract}

\section{Introduction}

It is very important for language learners to understand the true customs of the language and to enhance their ability to understand the culture of the country. In the process of learning Japanese, Japanese culture and education should be cut into the use of Japanese language teaching theory to study the cultural and educational related issues. In order to let the students realize that the Japanese people because of the seasonal sense of living habits, should complement the content of teaching, by allowing college students in the classroom teaching in-depth experience and exchanges, thereby enhancing its comprehensive understanding of the Japanese culture.

\section{Japanese and Japanese culture overview}

Language refers to the development of society to the corresponding degree of communication tools, language formation will be the national culture and geographical environment and many other factors. Japanese is a very valuable spiritual wealth produced by the great and the nation in the long term development. It is also the concrete manifestation of the Japanese culture in the outside and the important carrier of the communication and communication of the language. The development of Japanese culture has been deeply influenced by the culture of our country, and it has been combined with Japanese culture when we absorb Chinese culture. Because Japan and our country are in the geographical environment and human environment, the difference is increasing, and in the long period of cultural change, Which gradually formed a very unique culture, and Japanese just to reflect the distinctive characteristics of the island culture. Japanese has two characteristics: one is the use of a considerable number of ellipses, taken by the simple or fuzzy approach, which also reflects the Japanese focus on thinking and effectively maintain the form of doing things. On the other hand is the use of honorifics more, reflecting the Japanese culture which respect the elders of the social order, while the use of honorifics is also the Japanese culture in the language of a comprehensive show.

\section{The Necessity of Integrating into Japanese Culture Education in Japanese Teaching}

In view of the increasing communication between China and Japan, the Japanese language teaching put forward new requirements, mainly in the past to cultivate learners listening, speaking, reading, 
writing and translation and other aspects of the ability. However, due to the current society for the level of language talent requirements are also rising, more and more attention to the ability of personnel to carry out communication and communication. The ultimate aim of Japanese education is to improve the ability of students to use various cultures to communicate. Although the Japanese word and grammar, listening and so on are important basis for Japanese teaching, but to understand the Japanese language and culture and the use of Japanese to communicate and exchange is the ultimate goal of Japanese teaching. In the process of implementing Japanese education, the integration of Japanese culture can better improve the effectiveness of Japanese education, so as to cultivate a compound Japanese professional talents, so that learners can immerse themselves in the Japanese cultural environment, so as to enhance learning Effectiveness. Of course, with the integration of Japanese culture, learners can learn from the Japanese language, to master the content of Japanese culture, so as to strengthen the Japanese culture has a cognitive, a comprehensive understanding of Japanese Japanese culture, so talent To better help students master the differences between Chinese and Japanese culture, and in the future language and cultural exchanges to maintain good communication and coordination and other habits.

\section{Some Suggestions on Developing Japanese Language Teaching with Japanese Culture and Education}

\section{Integrate Japanese cultural information into Japanese classroom education}

Before the teaching, Japanese teachers should be on the vocabulary, grammar and teaching materials to explain the contents of the comprehensive preparation, but also should grasp the textbooks involved in the Japanese culture of the relevant knowledge. Teachers should not only have a comprehensive grasp of the textbooks related to the content of Japanese culture, but also should be carefully consult the relevant information. In the teaching into the teaching before the students to be reasonable and reasonable introduction. For example, in teaching the words involved in the tea can be introduced when the Japanese tea ceremony related knowledge, but also and China's cultural customs to be compared, obtained in China and Japan, the same point of tea culture and different points to guide the study They have a clearer understanding of the Japanese tea ceremony, to enhance the learners for the content of teaching interest, so, in the subsequent words, grammar and text teaching process, the learners will be more willing to accept and understand. In the lecture, because of the differences in the context of social history and culture, language differences should be regarded as the focus of teaching content, such as Japanese "あな ta" must be used with caution, because the Japanese words in the expression "You" means mainly used in the other surname, can be expressed as "さ $ん$ ". On the contrary, the Chinese second person "you" use rate is very high. At the same time, in Japanese, there may be cultural differences caused by understanding and communication barriers and other issues. For example, after accepting help from others, there are often learners who say "ありが と う (thank you)" to reflect the gratitude, but the other side will feel unhappy, it is because the expression will make people should do so a feeling of. Therefore, the better expression should be " すみ ma せん (sorry)", after hearing the words of the other side will certainly feel very happy, this is because the exact meaning of this is "should not disturb you, too add to you In trouble ". Therefore, in the classroom teaching should let the students not only to master the Japanese language has the surface meaning, but also from the Japanese cultural background, pay attention to the implied behind the deep meaning of Japanese. If the knowledge of the Japanese culture introduced in the classroom can be closely related to the language used in the day, the learner's ability to use Japanese can naturally be significantly improved, so that the learner's subjective initiative can be fully mobilized, and thus greatly enhance the learning Effect, do things half and power times. Therefore, in the classroom teaching should also be added to the learners to introduce implied in language expression and behavior after the various cultural elements. For example, the Japanese usually bow in the process of communication, and bow the difference between the expression of the meaning of the 
difference is different. Greeting greetings when the general bow 30 degrees on the line, and in the expression of a certain apology to the need to bow 45 degrees, to the other side of the apology when you need to bow 90 degrees to show sincerity.

\section{Deepen the students' understanding of the Japanese language itself}

Compared with other countries, the Chinese people in learning Japanese because of a very strong advantage of Chinese characters, so beginners are easy to Japanese characters in the equate. Although some of the Chinese characters in Japanese can be equated with Chinese, the learning model is likely to be a potential obstacle for learners to apply Japanese. For example, "Sir" in Chinese is a respect for adult men, but in Japan it is used to call teachers, doctors, lawyers and accomplished artists. For example, call Nakashima described in Japanese as "Mr. Nakashima (なかやませんせい)". In the morning, when the Japanese greeted others in the morning, they would generally say"おはようご います" or "おはよう". This is equivalent to the Chinese "Good morning", but the two sentences in Japanese are different. In the face of elders or leaders, or those who are not close enough, the former is used; in the face of the younger generation or with their own status equal, or more intimate person, the latter may be the latter. The difference is difficult to reflect in Chinese. In addition, some Japanese ladies said their husband as "あなた", and beginners Japanese people in communication with the Japanese easy to use Chinese thinking with this call, the result will cause each other embarrassment and even dissatisfaction, the subtle differences in Chinese is also very Hard to reflect. Therefore, Japanese teachers in the teaching can not just a word, sentence professor to the students, let him rote, but to design specific scenes, so that learners can grasp the background behind each of the cultural knowledge background The

\section{To guide learners to understand and adapt to the differences between different cultures in China and Japan}

Language can be said to be one of the most important carriers of culture, all languages are difficult to leave the culture and exist alone, the relationship between the two can not be separated. Although the cultural exchange between China and Japan is very long, but the two countries due to national character, geographical environment and other differences, so also produce their own different cultures. Once do not understand the characteristics of each other culture, it is easy to communicate in the many misunderstandings. Japanese learners should master the differences between Chinese and Japanese cultures in their studies, so as to cultivate their adaptability to Japanese culture. Only then can Japanese learners master Japanese knowledge and carry out cross-cultural communication activities better. To this end, we must grasp the following three points: First, for the different cultural exchange implementation of specialized exercises. In the conduct of different cultural exchanges, the same phenomenon is different views are normal, find and find all kinds of thinking ability is extremely important. In the event of cultural frictions, a specific scenario of cross-cultural friction should be comprehensively described in the process of group discussions, the reasons for it, discuss how to solve the problem, and avoid friction. After all kinds of discussion, learners can achieve different cultural differences in their studies. In the training process, the teacher does not just come to the standard answer on the line, but to enhance the learners to take the initiative to think about the ability. The second is to compare the language to find the difference between different cultures. Because of cultural differences, there is a great difference in the expression of language. By comparing the two languages, you can find out the differences in expression, and then deepen the understanding of different cultures. Such as, in recognition of others, in Chinese is "Xiao Zhang today is beautiful", and in Japanese is "really beautiful by the United States today." This small difference, in fact, reflects the Japanese to each other as the center, subtle and rigorous distinctive features, attaches great importance to their own attitudes and judgments on the other side caused by psychological barriers. Once in Japanese, "really beautiful by the United States today," then be praised not only will not be happy, but also feel that I am not enough before the United States? Third, deepen the understanding of different cultures, to promote two-way learning. Japanese language teaching is not 
just to teach learners' Japanese culture and how to express it, but to enable learners to discover differences between cultures and respect different cultures and create good conditions to promote two-way learning.

\section{The use of new material to carry out the integration of Japanese culture in Japanese language teaching}

The new source of material is mainly based on the Tokyo area-based Kanto local culture. Because Tokyo's living habits and the Osaka region as the center of the Kansai culture had a great difference, so it is necessary in the teaching of the students to remind. At the same time, because Japanese teachers in the introduction of Japanese culture, there are some limitations, so that students in the classroom before learning the contents of the classroom to find more important. At the same time, the use of students in the pre-class content, will be able to learn in the classroom to create a specific time to discuss, so that the specific content of the implementation of a more comprehensive and in-depth understanding, so that it can appreciate the Japanese culture Between the same point and the difference. In this case, the Japanese traditional Chinese Yuan Festival, for example, the integration of the Japanese culture of Japanese teaching method to be sorted out. First, should be in the teaching before the learners in advance for the elements of the relevant elements to be found. Second, should be in the process of Japanese teaching, teachers must first use the pre-prepared physical and content of the students to introduce. In this process, should be and our traditional sense of the gift custom to be compared. Third, the implementation of the group discussion. In order to allow learners to find what they are and the content of the teacher to compare the content. Followed by a specific panel discussion. Four by the group representatives to speak. After the end of the panel discussion, the team delegates made a statement on the specific content discussed and supplemented by the team members. The use of this form, so that learners can fully and accurately understand the meaning of the meta-section. Fifth is the arrangement of operations. Let the learners choose the content of the most interesting content from the content of the Japanese classroom teaching and write them in Japanese, such as「私の知っているお中元」 and so on. The use of classroom teaching before the preparation of classroom teaching observation and experience, exchange, so that students for the Japanese culture to implement multi-angle, multi-faceted understanding, so that it can let the understanding of the same between the Sino-Japanese culture And the difference, so that students can effectively cultivate the understanding of other countries' culture. In the process of implementing cultural teaching, we should pay attention to cultivating the students' understanding and the understanding of the same and different cultures of China and Japan. This naturally puts forward new demands to Japanese teachers.

\section{Conclusions}

In summary, the ultimate purpose of Japanese education is to be able to use Japanese for smooth communication. Those who are engaged in Japanese teaching must earnestly respect the cultural habits of the students and guide students to discover the differences and similarities between their culture and Japanese culture. On this basis, the students are fully promoted to deepen the understanding of Japanese culture, through continuous learning and growth, by further improving the various aspects of Japanese culture and education teaching methods, so as to promote the exchange between Chinese and Japanese culture to make new The contribution.

\section{References}

[1] Tong Yanli. Japanese and Japanese culture - Japanese language teaching in the introduction of Japanese culture, Science and Technology Information, 2012 (3).

[2] Luo Chuanwei. Japanese teaching in the introduction of Japanese culture and education is imperative, Foreign Language Teaching, 2013 (4). 
[3] Liu Yu. On the Japanese language education in the Japanese culture, Innovative education, 2012 (13).

[4] Wang Huijie. On Japanese University Japanese language education and culture, Journal of Jilin Institute of Engineering Technology, 2013 (11).

[5] Ye Erling. Exploring the Current Situation of Japanese Culture from Japanese Education Comment on "Japanese Language Teaching and Japanese Culture Studies", University Education Science, 2016 (3). 